\title{
The Association Between Oral Lichen Planus and Hepatitis C Virus Infection; A Report From Northeast of Iran
}

\author{
Sina Gerayli ${ }^{1}$; Zahra Meshkat ${ }^{2}$; Alireza Pasdar ${ }^{3,4}$; Pegah Mosannen Mozafari ${ }^{5,{ }^{*}}$; Elham \\ Banihashemi ${ }^{5}$; Mohammad Amin Khajavi ${ }^{5}$; Javid Rasekhi ${ }^{5}$ \\ ${ }^{1}$ Department of Biology, Faculty of Sciences, Ferdowsi University of Mashhad, Mashhad, IR Iran \\ ${ }_{3}^{2}$ Antimicrobial Resistance Research Center, Mashhad University of Medical Sciences, Mashhad, IR Iran \\ 3 Department of Modern Sciences and Technologies, Faculty of Medicine, Mashhad University of Medical Sciences, Mashhad, IR Iran \\ ${ }_{5}^{4}$ Division of Applied Medicine, Medical School, University of Aberdeen, Foresterhill, Aberdeen, UK \\ ${ }^{5}$ Oral and Maxillofacial Diseases Research Center, School of Dentistry, Mashhad University of Medical Sciences, Mashhad, IR Iran \\ *Corresponding author: Pegah Mosannen Mozafari, Oral and Maxillofacial Diseases Research Center, School of Dentistry, Mashhad University of Medical Sciences, Mashhad, IR Iran. \\ Tel:+98-5138829501, Fax:+98-5138829500, E-mail: mosannenp@mums.ac.ir
}

Received: December 9, 2013; Revised: May 6, 2014; Accepted: June 24, 2014

\begin{abstract}
Background: The association between hepatitis C virus (HCV) infection and oral lichen planus (OLP) has been the focus of many studies. Fifteen percent of HCV infections lead to sets of extrahepatic manifestations including lichen planus (LP). The prevalence of HCV is heavily influenced by geographical location.

Objectives: This study aimed to evaluate the relationship between OLP and HCV infection in Mashhad, northeast of Iran.

Materials and Methods: Blood samples were taken from 134 OLP patients and 134 healthy controls (without OLP) to screen for anti-HCV by ELISA(third generation) and reverse transcription polymerase chain reaction (RT-PCR) for HCV-RNA.

Results: Of the 134 OLP patients only three (2.23\%) had HCV infection where both anti-HCV and HCV-RNA were positive. All controls were negative for both anti-HCV and HCV-RNA $(\mathrm{P}=0.082)$.

Conclusions: Our investigation illustrated that the prevalence of hepatitis $\mathrm{C}$ was higher among OLP patients compared to the control group. These findings are in line with previous results that reported a hepatitis C prevalence of $0.19 \%$ among the general population of Mashhad.
\end{abstract}

Keywords: Hepatitis C; Viral Infections; Lichen Planus, Oral; Epidemiology; Iran; anti-HCV; HCV-RNA

\section{Background}

Hepatitis C virus (HCV), being discovered by Patrick in 1989, belongs to the family Flaviviridae and has a positive sense single-stranded RNA genome (1). Almost 170 million people are infected by this virus worldwide. It is estimated that $3 \%$ of the world's population are carriers of this virus and three to four million new infections occur annually (2), making this infection a global issue (3). About $70 \%$ to $80 \%$ of infected patients enter the chronic phase of the disease, more than $50 \%$ of which are asymptomatic (4). Hepatitis C virus is known to be a major leading cause of chronic hepatic diseases and hepatocellular carcinoma. However, the virus-induced disorders are not limited to hepatic diseases; $15 \%$ of cases lead to sets of extra hepatic manifestations including glomerulonephritis, lymphoma, leukemia, Sjogren's syndrome and lichen planus (5-7). Epidemiological studies have revealed that there is a high incidence rate of extra hepatic manifestations in hepatitis $\mathrm{C}$ carriers, induced by immune reaction to the virus (2). Several studies have also reported epidemiological and genotypic data on hepatitis $C$ virus in Iran, indicating that $1 \mathrm{a}, 3 \mathrm{a}$ and $1 \mathrm{~b}$ were the most prevalent genotypes in Shiraz city, while there was a high prevalence of HCV infection amongst hemophilic patients in Isfahan city (8-10).

Lichen planus (LP) is a chronic mucocutaneous disease commonly seen in dermatological and dentistry clinics (11-14). The disease was first reported by Wilson in 1869 . Several investigations have reported its prevalence as $0.76 \%$ to $2.2 \%$ (11). Sometimes LP occurs with other systemic diseases such as immune disorders, infections and malignancies. Nonetheless, the relationship between these factors and the disease has remained unknown (15). Lichen planus involves either or both skin and mucous membranes. Dermal lesions are mainly in limb extremities, genital area, nails, facial areas and head. These lesions are observed as smooth pruritic, polygonal purple

Copyright (C) 2015, Ahvaz Jundishapur University of Medical Sciences. This is an open-access article distributed under the terms of the Creative Commons Attribution-NonCommercial 4.0 International License (http://creativecommons.org/licenses/by-nc/4.0/) which permits copy and redistribute the material just in noncommercial usages, provided the original work is properly cited. 
papules. Mucosal lesions develop in oral cavity (with higher prevalence), nose, throat, esophagus, stomach, urinary bladder and the genital region $(16,17)$. Oral lichen planus (OLP) usually occurs bilaterally on the buccal mucosa and frequently involves the tongue, mucobuccal fold, gingiva and other sites. Oral lichen planus involves women 1.4 times more than men, mostly between the ages of 50 to 60 (16-18).

There are different clinical forms of OLP, such as atrophic, bullous and erosive. The disease is usually asymptomatic and is diagnosed by routine oral examinations. Sometimes patients complain of pain or irritation or a feeling of roughness of mucosa. Clinical manifestations, development and the affected region may differ with time, even in the same individual (19). The etiology is still unknown, however many researchers blame genetic and environmental factors such as medicines that induce this disorder (19). Primary reports on the association of OLP and chronic liver disease were published by Rebora and Rongioletti (20) and Rebora et al. (21). In a few Asian regions such as Turkey and Thailand, some studies have shown a relationship between hepatitis C and OLP, indicating something more than simply a coincidental event $(22,23)$.

\section{Objectives}

The present study aimed to distinguish the relationship between OLP and hepatitis C in Mashhad, northeast of Iran.

\section{Materials and Methods}

\subsection{Study Population}

All patients were from Mashhad and had referred to the dental clinic of Mashhad University of Medical Science. The research protocol was approved by the Ethics Committee of Mashhad University of Medical Sciences in October 2012 and was registered under code 910620. A written informed consent was obtained prior to recruitment. The archive of 580 patients with OLP who were referred to the Department of Oral Medicine, Mashhad Dental School, was reviewed by the researchers and patients with possibility of lichenoid reaction (due to drug or dental restorations) were excluded $(\mathrm{N}=150)$. Of the remaining patients, 430 with valid contact information were recruited. Two hundred cases responded and attended the Oral Medicine Clinic. Total improvement was observed in four patients.

After clear disclosure of the research protocol, 66 patients denied contribution to the study, thus finally 134 patients were included in this study. Clinical diagnosis of these patients was based on typical clinical features and was approved histopathologically in suspected cases. Controls were selected from all individuals who were referred to the Imam Reza medical laboratory and consented to be included in the study. Their oral cavity was examined by two dentists to exclude OLP lesions. A blood sample was then obtained from each individual. The medical history of all recruited patients and controls were investigated and all available information about a previous history of viral hepatitis and risk factors for liver diseases i.e. episodes of jaundice, acute hepatitis, liver dysfunction, previous surgery, blood transfusion, smoking habits, alcohol consumption, intravenous drug abuse and other risks of HCV infection such as history of tattoos and family history of liver disorders, were recorded.

\subsection{Laboratory Methods}

A $5 \mathrm{~mL}$ blood sample was obtained from each individual in order to measure serum levels of alanine aminotransferase (ALT), aspartate aminotransferase (AST), alkaline phosphatase (ALP) and bilirubin by standard laboratory methods. In addition, third-generation ELISA was used as the screening test to find anti-HCV antibodies. If a serum sample was positive for HCV antibody, confirmation was done by reverse transcription polymerase chain reaction (RT-PCR), as a specific test, to find HCV-RNA. In the RT-PCR method, the viral genome was extracted using a viral RNA extraction kit (Roche, Germany). After genome extraction, viral RNA was detected using the HCV specific commercial kit (STRP Hepatitis C Virus Detection Kit, CinnaGen Co., Iran). The PCR products were visualized on a $1.5 \%$ agarose gel by green viewer staining (Pars Tous, Iran) and UV photography.

\subsection{Statistical Analysis}

To compare relative frequencies in cases and controls, the chi-square test was used. Using the SPSS software version21, the data sets were examined for normality by the KS test. For data with normal distribution, independent samples t-test was used to compare mean differences. Nonparametric tests were used to compare the means of the dataset, which did not have a normal distribution. Corresponding P-values were considered significant at values $<0.05$. Other data, such as gender, types and locations of the OLP lesions, were expressed as percentages.

\section{Results}

Population data, medical histories and liver function tests of the patients with OLP and controls are shown in Table 1 . The average age of the patients was $51.60 \pm 12.03$ years $(M=55.37 \pm 11.88$ years; range: 31 to 76 years, $F=49.95$ \pm 11.79 years; range: 20 to 82 years) and the average age of the controls was $45.61 \pm 17.51$ years $(\mathrm{M}=47.48 \pm 16.78$ years; range: 15 to 93 years, $\mathrm{F}=44.18 \pm 18.03$ years; range: 12 to 86 years) respectively. Table 2 illustrates the site and type of OLP involvement in our case group. Most lesions were reticular (31.3\%), which are usually observed in buccal mucosa (76.9\%).

Duration of the OLP period ranged from three months 
to 108 months and the mean duration of disease was $34.24 \pm 23.08$ months. Furthermore, $24.62 \%$ of patients had abnormal liver function tests (LFT). Abnormal LFT was found in $31.34 \%$ of controls. No positive anti HCV was found in the control group whereas three positive samples in OLP patients were assessed for HCV RNA. The RTPCR confirmed HCV infection in these patients. Although HCV infection was more frequent in cases, this difference was not statistically significant $(P=0.082)$. The three
HCV positive patients in the OLP group were addicted to parenteral crack; one of them had the atrophic-erosivereticular form and the two others had the atrophic-erosive form of lichen planus. Details on clinical and laboratory findings in patients with OLP associated with HCV are demonstrated in Table 3. In addition, we divided all OLP patients to five groups according to their lesion size (Table 4). Size of lesions was not related to HCV infection $(\mathrm{P}>0.05)$.

Table 1. The Demographic Data of OLP and Control Group ${ }^{\text {a }}$

\begin{tabular}{|c|c|c|c|}
\hline Characteristics & Patients & Controls & P Value \\
\hline M:F & $41: 93$ & $58: 76$ & $0.031^{b}$ \\
\hline Age, $y$ & $51.60 \pm 12.03$ & $45.61 \pm 17.51$ & $0.003^{b}$ \\
\hline Dermatologic Disorder & $8(5.97)$ & $0(0)$ & $0.004^{b}$ \\
\hline Blood Transfusion & $8(5.97)$ & $2(1.49)$ & 0.053 \\
\hline Addiction & $3(2.23)$ & 0 & 0.08 \\
\hline Smoking & $3(2.23)$ & $2(1.49)$ & 0.65 \\
\hline Alcohol & $2(1.49)$ & 0 & 0.16 \\
\hline Allergy & $7(5.22)$ & $1(0.74)$ & $0.03^{b}$ \\
\hline Family history of Liver Disorder & $8(5.97)$ & $1(0.74)$ & $0.02^{b}$ \\
\hline Diabetes & $29(21.67)$ & $27(20.14)$ & 0.76 \\
\hline Hypertension & $30(22.38)$ & $26(19.40)$ & 0.55 \\
\hline Heart Disease & $16(11.94)$ & $9(6.71)$ & 0.14 \\
\hline Lung Disease & $4(2.98)$ & $1(0.74)$ & 0.18 \\
\hline Kidney Disease & $2(1.49)$ & $8(5.97)$ & 0.052 \\
\hline Anemia & 15 (11.19) & $13(9.70)$ & 0.7 \\
\hline Previous Surgery & $33(24.62)$ & $9(6.71)$ & $<0.0001^{b}$ \\
\hline Arthritis & $6(4.47)$ & $2(1.49)$ & 0.15 \\
\hline Jaundice & $2(1.49)$ & $0(0)$ & 0.15 \\
\hline Liver Dysfunction & $5(3.73)$ & $1(0.74)$ & 0.1 \\
\hline Organ transplant & $0(0)$ & $6(4.47)$ & $0.01^{\mathrm{b}}$ \\
\hline AST, $\mathbf{U ~ I}^{\mathbf{- 1}}$ & $20.67 \pm 13.27$ & $22.25 \pm 7.55$ & $<0.001^{\mathrm{b}}$ \\
\hline ALT, $\mathbf{U ~ I}^{-\mathbf{1}}$ & $19.77 \pm 6.97$ & $21.03 \pm 18.13$ & $<0.0001^{\mathrm{b}}$ \\
\hline ALP, $\mathbf{U}^{\mathbf{- 1}}$ & $209.86 \pm 67.95$ & $239.37 \pm 121.62$ & 0.08 \\
\hline Total Bilirubin, U I-1 & $0.69 \pm 0.34$ & $0.59 \pm 0.25$ & $0.008^{\mathrm{b}}$ \\
\hline Direct Bilirubin, $\mathrm{U}^{\mathbf{- 1}}$ & $1.63 \pm 0.73$ & $1.44 \pm 0.65$ & $0.02^{\mathrm{b}}$ \\
\hline
\end{tabular}

a Data are presented as No. (\%) or mean \pm SD.

b Significant difference. 


\begin{tabular}{lc}
\hline \multicolumn{2}{l}{ Table 2. Types and Sites of the Lesion in the OLP Patients $\mathrm{a}, \mathrm{b}$} \\
\hline \multicolumn{1}{l}{ Variables } & \multicolumn{1}{l}{ Values } \\
\hline \multicolumn{1}{l}{ Types } \\
\hline Atrophic-erosive & $9(6.7)$ \\
\hline Reticular & $42(31.3)$ \\
\hline Papular & $6(4.5)$ \\
\hline Pigmented & $4(3)$ \\
\hline Bullous & $0(0)$ \\
\hline Atrophic-erosive-Reticular & $63(47)$ \\
\hline Pigmented-Atrophic-erosive & $2(1.5)$ \\
\hline Pigmented-Reticular & $4(3)$ \\
\hline Pigmented-Atrophic-erosive-Reticuler & $4(3)$ \\
\hline Sites & $103(76.9)$ \\
\hline Buccal mucosa & $54(40.3)$ \\
\hline Mucobuccal fold & $36(26.6)$ \\
\hline Gingiva & $22(16.4)$ \\
\hline Lips & $48(35.8)$ \\
\hline Tongue & $4(3)$ \\
\hline Floor of the mouth & $7(5.2)$ \\
\hline Palate & \\
\hline a Data are presented No. (\%). \\
bach patient might have more than one type and site of OLP.
\end{tabular}

Table 3. Clinical Findings and Laboratory Results of Patients With OLP Associated With HCV a

\begin{tabular}{lcccccc}
\hline Sites & $\begin{array}{c}\text { Duration } \\
\text { of OLP }\end{array}$ & AST & ALT & ALP & $\begin{array}{c}\text { Total } \\
\text { Bilirubin }\end{array}$ & $\begin{array}{c}\text { Direct } \\
\text { Bilirubin }\end{array}$ \\
\hline M,T & 74 & 45 & 52 & 367 & 1 & 0.1 \\
B & 45 & 58 & 50 & 342 & 1.4 & 0.2 \\
T & 60 & 40 & 28 & 275 & 0.8 & 0.1 \\
\hline
\end{tabular}

a B, buccal mucosa; $\mathrm{M}$, mucobuccal fold; $\mathrm{T}$, tongue.

\begin{tabular}{lc}
\hline Table 4. Classification of Lesion Sizes ${ }^{\mathrm{a}}$ \\
\hline Variables & Values \\
\hline Total area of involvement $<\mathbf{3 \mathbf { ~ c m } ^ { 2 }}$ & $51(38.1)$ \\
\hline Total area of involvement $<\mathbf{6} \mathbf{~ c m}^{2}$ & $29(21.6)$ \\
\hline Total area of involvement $<\mathbf{1 0} \mathbf{~ c m}^{2}$ & $27(20.1)$ \\
\hline Total area of involvement $<\mathbf{1 5} \mathbf{~ c m}^{2}$ & $12(9)$ \\
\hline Total area of involvement $>\mathbf{1 5} \mathbf{~ c m}^{2}$ & $15(11.2)$ \\
\hline a Data are presented as No.(\%).
\end{tabular}

a Data are presented as No.(\%).

\section{Discussion}

The prevalence of hepatitis $\mathrm{C}$ virus has been reported as $0.13 \%$ among the population of Mashhad (Northeast of Iran) (24). According to a systematic review on global prevalence of anti-HCV, Central and East Asia and North Africa/Middle East were estimated to have a high preva- lence (>3.5\%), while Asia Pacific, Tropical Latin America and North America had a low prevalence $(<1.5 \%)$ of hepatitis C (25). On the other hand, there are many published studies about the prevalence of OLP worldwide. In a previous study by Pakfetrat et al. the prevalence of OLP in our area was reported as $18.2 \%$ among patients who were referred to the Oral Medicine Clinic of Mashhad Dental School (26). Prevalence of OLP has also been reported as $0.5 \%$ among textile workers in Iran (27). The prevalence of hepatitis C infection in patients with LP is highly variable (from $8.3 \%$ in France to $62 \%$ in Japan). Several reports have also demonstrated that $2.4 \%$ to $8 \%$ of patients with chronic hepatic diseases (related to hepatitis $\mathrm{C}$ ) also have LP (28-30). The infection rate varies in different countries $(31,32)$.

Data about the true relationship between these two conditions is controversial. Some studies have proved this relationship, while others indicate the contrary (3338). Several investigations have shown a relationship between LP and hepatitis B and C. A large Italian survey on 577 patients from various regions showed that one fifth of people affected by LP, were positive for HCV antibody, while only $3.2 \%$ of the control group were positive. In another study conducted in Italy, 263 OLP patients underwent HCV antibody detection and it was revealed that 66 cases (28.6\%) were positive for HCV (39). Similar studies from other countries in this region have also reported this relationship. In countries such as Pakistan (35) and Saudi Arabia (33), a concurrent relationship between LP and hepatitis $C$ has been reported as well, while, a Turkish study did not find any relationship (34). In Taiwan, Chung et al. showed that OLP was significantly related to hepatitis C (40). In Iran, two studies in Kerman (41) and Hamadan (42), showed that LP was not associated with hepatitis $C$ virus infection. According to a study conducted in Tehran during 1997 to 1998, 146 people with LP were investigated for HCV antibody. Seven cases (4.8\%) were positive and a significant relationship was observed between these two disorders (38).

There are also similar studies in other parts of the world. In a study on 47 LP cases in England, none of the patients were antibody positive for HCV, however, it was concluded that it was not necessary to assess HCV antibody in this country (37). Evaluation of HCV on 36 LP patients in Spain revealed that only one case (2.77\%) was positive for HCV antibody, and no significant relationship was observed between LP and hepatitis C (43). In an investigation conducted in Nigeria on 57 LP patients, one case was diagnosed positive for HCV antibody, and it was observed that prevalence of hepatitis $C$ in patients with LP was much less than other dermatosis conditions yet higher than healthy individuals. Therefore, no relationship was found between LP and hepatitis C (44). In the present study, the prevalence of HCV RNA and anti-HCV among the OLP patients was $2.23 \%$ while there was no HCV infection detected in controls. This finding is similar to previous studies and suggests a relationship between 
OLP and HCV infection although this difference was not significant $(\mathrm{P}=0.08)$.

The difference in reported associations between LP and hepatitis B and C may be due to the following reasons; firstly, geographical differences could be due to the various genetic susceptibilities of the hosts. Variations in genetic factors in different populations may be responsible for OLP presentation. For example, interferon $\gamma$ genetic polymorphism and tumor necrosis factor $\alpha$ variation can affect OLP incidence $(45,46)$. Secondly, differences in prevalence of HCV infection in LP cases with geographic and ethnic variations may be related to immunological factors such as HLA-DR6 allele, which is particularly observed in some countries $(47,48)$. This allele is frequently observed in Italian patients with OLP and hepatitis C. Based on these variations, concurrent incidence of LP and hepatitis $C$ infection in Japan and Italy is high, while it is reported to be low in America and Germany. Therefore, changes in hepatitis $C$ infection incidence may be the reason for differences in the incidence of this disease in LP affected people (32). Thirdly, the difference in the prevalence of the two diseases in various regions can be responsible for different coincidence or relationship of the two entities. High prevalence of hepatitis C in Italy can impact this relationship. Fourthly, different criteria for diagnosis of OLP can affect findings. In our study clinical and histopathological evidence of involvement was used to affirm diagnosis of OLP. Lastly, some cases of lichenoid reaction may be misdiagnosed as OLP and this can affect the estimation of the true frequency of OLP. We excluded these cases in our survey.

The virus RNA is found in saliva, serum, skin lesions and even oral tissues of involved HCV patients, this can suggest a cause-effect relationship between the two diseases $(2,3)$. Therefore, two general hypotheses exist about lichen planus in patients with hepatitis $C$ virus; the first hypothesis is that the virus is capable of duplication, development and proliferation in oral epithelium and contributes to emergence of OLP in oral cavity. The second, claims that hepatitis $C$ virus is able to mutate very well and therefore causes more activation of immune cells and probable reaction of body against intrinsic tissues, which in turn raises autoimmune reactions (49). Some literature reports have also attributed the LP incidence in hepatitis $C$ affected patients to the cytotoxicity of hepatocytes (50).

The results of the present study illustrates that a nonsignificant relationship exists between OLP and hepatitis C. It is recommended to evaluate more OLP patients to validate such relationship. It appears that the prolonged period of hepatitis $C$ and an attenuated immune system lead to an increase of hepatic enzymes and consequent OLP lesions. Thus, chronic hepatitis $C$ may be one of the rationales behind the relationship of OLP and HCV infection in our population. However, the mechanism of this relationship is still unclear and more studies are required in this field. Nonetheless, the prompt diagnosis of many viruses such as most viral hepatitis family viruses may help achieve a better level of control of the disease and more effective treatments. At least, HCV detection in high-risk patients (e.g. evidence of liver disease, drug addiction etc.) with OLP can improve treatment outcomes. Our study did not show any significant difference in demographic factors, such as smoking, alcohol consumption and diabetes between the two groups. This might be because of the sample size of this research. However, a bigger sample size may further clarify our findings. Therefore, we recommend similar researches in various geographical locations with bigger sample sizes to support these findings. We also recommend a study on the prevalence of palatal lichen planus amongst hepatitis $C$ patients. Such studies can illustrate this relationship further and can underline the need for serological tests for people with palatal lichen planus to rule out hepatitis $\mathrm{C}$ infections.

\section{Acknowledgements}

The authors would like to thank all patients who contributed to this investigation.

\section{Authors' Contributions}

Sina Gerayli: designed the study, performed the laboratory tests and prepared the preliminary manuscript. Alireza Pasdar: analyzed the data and revised the manuscript. Elham Banihashemi and Mohammad Amin Khajavi: performed the clinical evaluation of OLP patients and controls, and helped with data collection. Pegah Mosannen Mozafari and Zahra Meshkat: granted the entire study and developed the original idea and the protocol.

\section{Funding/Support}

This study was supported by a grant from the Vice Chancellor for Research of Mashhad University of Medical Sciences, Mashhad, Iran (grant no. 910620).

\section{References}

1. Patrick L. Hepatitis C: epidemiology and review of complementary/alternative medicine treatments. Altern Med Rev. 1999;4(4):220-38.

2. Carrozzo M, Gandolfo S. Oral diseases possibly associated with hepatitis C virus. Crit Rev Oral Biol Med. 2003;14(2):115-27.

3. Maticic M. Hepatitis C virus infection: the dermatological perspective. Acta Dermatovenerol Alp Pannonica Adriat. 2003;12(1):19-27.

4. Harden D, Skelton H, Smith KJ. Lichen planus associated with hepatitis $C$ virus: no viral transcripts are found in the lichen planus, and effective therapy for hepatitis $C$ virus does not clear lichen planus. J Am Acad Dermatol. 2003;49(5):847-52.

5. Lodi G, Giuliani M, Majorana A, Sardella A, Bez C, Demarosi F, et al. Lichen planus and hepatitis $C$ virus: a multicentre study of patients with oral lesions and a systematic review. BrJ Dermatol. 2004;151(6):1172-81.

6. Prabhu S, Pavithran K, Sobhanadevi G. Lichen planus and hepatitis c virus (HCV)--is there an association? A serological study of 65 cases. Indian J Dermatol Venereol Leprol. 2002;68(5):273-4.

7. Lodi G, Olsen I, Piattelli A, D'Amico E, Artese L, Porter SR. Antibodies to epithelial components in oral lichen planus (OLP) asso- 
ciated with hepatitis C virus (HCV) infection.J Oral Pathol Med. 1997;26(1):36-9.

8. Jamalidoust M, Namayandeh M, Asaei S, Aliabadi N, Ziyaeyan M. Determining hepatitis $C$ virus genotype distribution among high-risk groups in Iran using real-time PCR. World J Gastroenterol. 2014;20(19):5897-902

9. MaziarMojtabavi N, Fatemeh D, Hamid H, Roya D, FariborzMakarian R. Analysis of the related factors in hepatitis C virus infection among hemophilic patients in Isfahan, Iran. Hepat Mon. 2007;7(2):59-62.

10. Alavian SM, Jabbari H, Daryani NE. Hepatitis C Virus: The Rising Concerns and Growing Hopes, Report From the HCV Symposium, Fourth Tehran Hepatitis Congress, November 2011, Tehran, Iran. Hepat Mon. 2012;12(7):423.

11. Regezi JA, Sciubba JJ, Jordan RCK. Oral Pathology: Clinical Pathologic Correlations.San Diego: Elsevier Health Sciences; 2012.

12. Neville BW, Damm DD, Allen C, Bouquot JE. Oral and Maxillofacial Pathology: Pageburst Retail.netherlands: Elsevier Science Health Science Division; 2008.

13. Eisen D. The clinical features, malignant potential, and systemic associations of oral lichen planus: a study of 723 patients. J Am Acad Dermatol. 2002;46(2):207-14.

14. Rossi L, Colasanto S. [Clinical considerations and statistical analysis on 100 patients with oral lichen planus]. Minerva Stomatol. 2000;49(9):393-8.

15. Campisi G, Fedele S, Lo Russo L, Di Fede O, Arico P, Craxi A, et al. HCV infection and oral lichen planus: a weak association when HCV is endemic. J Viral Hepat. 2004;11(5):465-70.

16. Burket LW, Greenberg MS, Glick M, Ship JA. Burket's Oral Medicine.USA: BC Decker; 2008.

17. Machado AC, Sugaya NN, Migliari DA, Matthews RW. Oral lichen planus. Clinical aspects and management in fifty-two Brazilian patients. West Indian Med J. 2003;52(3):203-7.

18. Sugerman PB, Savage NW. Oral lichen planus: causes, diagnosis and management. Aust Dent J. 2002;47(4):290-7.

19. Thongprasom K, Carrozzo M, Furness S, Lodi G. Interventions for treating oral lichen planus. Cochrane Database Syst Rev. 2011(7):CD001168.

20. Rebora A, Rongioletti F. Lichen planus and chronic active hepatitis. J Am Acad Dermatol. 1984;10(5):840-1.

21. Rebora A, Robert E, Rongioletti F. Clinical and laboratory presentation of lichen planus patients with chronic liver disease.J Dermatol Sci. 1992;4(1):38-41.

22. Klanrit P, Thongprasom K, Rojanawatsirivej S, Theamboonlers A, Poovorawan Y. Hepatitis C virus infection in Thai patients with oral lichen planus. Oral Dis. 2003;9(6):292-7.

23. Kirtak N, Inaloz HS, Erbagci Z, Ozgoztasi.. The prevalence of hepatitis $C$ virus infection in patients with lichen planus in Gaziantep region of Turkey. Eur J Epidemiol. 2000;16(12):1159-61.

24. Shakeri MT, Foghanian B, Nomani H, Ghayour-Mobarhan M, Nabavinia MS, Rostami S, et al. The prevalence of hepatitis B virus infection in mashhad, iran: a population-based study. Iran Red Crescent Med J. 2013;15(3):245-8.

25. Mohd Hanafiah K, Groeger J, Flaxman AD, Wiersma ST. Global epidemiology of hepatitis C virus infection: new estimates of age-specific antibody to HCV seroprevalence. Hepatology. 2013;57(4):1333-42.

26. Pakfetrat A, Javadzadeh-Bolouri A, Basir-Shabestari S, Falaki F. Oral Lichen Planus: a retrospective study of 420 Iranian patients. Med Oral Patol Oral Cir Bucal. 2009;14(7):E315-8.

27. Jahanbani J. Prevalence of oral leukoplakia and lichen planus in 1167 Iranian textile workers. Oral Dis. 2003;9(6):302-4.

28. Chuang TY, Stitle L, Brashear R, Lewis C. Hepatitis C virus and lichen planus: A case-control study of 340 patients. J Am Acad Dermatol. 1999;41(5 Pt 1):787-9.

29. Carrozzo M, Gandolfo S, Carbone M, Colombatto P, Broccoletti $\mathrm{R}$, Garzino-Demo P, et al. Hepatitis C virus infection in Italian patients with oral lichen planus: a prospective case-control study. J
Oral Pathol Med. 1996;25(10):527-33.

30. Bagan JV, Aguirre JM, del Olmo JA, Milian A, Penarrocha M, Rodrigo JM, et al. Oral lichen planus and chronic liver disease: a clinical and morphometric study of the oral lesions in relation to transaminase elevation. Oral Surg Oral Med Oral Pathol. 1994;78(3):337-42.

31. Jubert C, Pawlotsky JM, Pouget F, Andre C, DeForges L, Bretagne S, et al. Lichen planus and hepatitis $C$ virus-related chronic active hepatitis. Arch Dermatol. 1994;130(1):73-6.

32. Nagao Y, Sata M. Hepatitis $C$ virus and lichen planus. J Gastroenterol Hepatol. 2004;19(10):1101-13.

33. Asaad T, Samdani AJ. Association of lichen planus with hepatitis C virus infection. Ann Saudi Med. 2005;25(3):243-6.

34. Karavelioglu D, Koytak ES, Bozkaya H, Uzunalimoglu O, Bozdayi AM, Yurdaydin C. Lichen planus and HCV infection in Turkish patients. Turk J Gastroenterol. 2004;15(3):133-6.

35. Mahboob A, Haroon TS, Iqbal Z, Iqbal F, Butt AK. Frequency of anti-HCV antibodies in patients with lichen planus. J Coll Physicians Surg Pak. 2003;13(5):248-51.

36. Garg VK, Karki BM, Agrawal S, Agarwalla A, Gupta R. A study from Nepal showing no correlation between lichen planus and hepatitis B and C viruses. J Dermatol. 2002;29(7):411-3.

37. Tucker SC, Coulson IH. Lichen planus is not associated with hepatitis $\mathrm{C}$ virus infection in patients from north west England. Acta Derm Venereol. 1999;79(5):378-9.

38. Ghodsi SZ, Daneshpazhooh M, Shahi M, Nikfarjam A. Lichen planus and Hepatitis C:a case-control study. BMCDermatol. 2004;4:6.

39. Mignogna MD, Lo Muzio L, Favia G, Mignogna RE, Carbone R, Bucci E. Oral lichen planus and HCV infection: a clinical evaluation of 263 cases. Int J Dermatol. 1998;37(8):575-8.

40. Chung CH, Yang YH, Chang TT, Shieh DB, Liu SY, Shieh TY. Relationship of oral lichen planus to hepatitis $\mathrm{C}$ virus in southern Taiwan. Kaohsiung J Med Sci. 2004;20(4):151-9.

41. Rahnama Z, Esfandiarpour I, Farajzadeh S. The relationship between lichen planus and hepatitis $\mathrm{C}$ in dermatology outpatients in Kerman, Iran. Int J Dermatol. 2005;44(9):746-8.

42. Ansar A, Zamanian A, Farschian M, Sorouri R, Mobaien AR. Comparison of seropositivity of HCV between oral lichen planus and healthy control group in Hamedan province (west of Iran). Our Dermatol Online. 2011;2(4):181.

43. Luis-Montoya P, Cortes-Franco R, Vega-Memije ME. [Lichen planus and hepatitis $\mathrm{C}$ virus. Is there an association?]. Gac Med Mex. 2005;141(1):23-5.

44. Daramola OO, George AO, Ogunbiyi AO. Hepatitis C virus and lichen planus in Nigerians: any relationship? Int J Dermatol. 2002;41(4):217-9.

45. Carrozzo M, Uboldi de Capei M, Dametto E, Fasano ME, Arduino $\mathrm{P}$, Broccoletti R, et al. Tumor necrosis factor-alpha and interferon-gamma polymorphisms contribute to susceptibility to oral lichen planus. J Invest Dermatol. 2004;122(1):87-94.

46. Bai J, Lin M, Zeng X, Zhang Y, Wang Z, Shen J, et al. Association of polymorphisms in the human IFN-gamma and IL-4 gene with oral lichen planus: a study in an ethnic Chinese cohort. J Interferon Cytokine Res. 2008;28(6):351-8.

47. Carrozzo M, Francia Di Celle P, Gandolfo S, Carbone M, Conrotto D, Fasano ME, et al. Increased frequency of HLA-DR6 allele in Italian patients with hepatitis $C$ virus-associated oral lichen planus. BrJDermatol. 2001;144(4):803-8.

48. Carrozzo M, Brancatello F, Dametto E, Arduino P, Pentenero M, Rendine S, et al. Hepatitis C virus-associated oral lichen planus: is the geographical heterogeneity related to HLA-DR6? J Oral Pathol Med. 2005;34(4):204-8

49. Chainani-Wu N, Lozada-Nur F, Terrault N. Hepatitis C virus and lichen planus: a review. Oral Surg Oral Med Oral Pathol Oral Radiol Endod. 2004;98(2):171-83.

50. Tanei R, Watanabe K, Nishiyama S. Clinical and histopathologic analysis of the relationship between lichen planus and chronic hepatitis C. J Dermatol. 1995;22(5):316-23. 